\title{
The burying and grazing effects of plateau pika on alpine grassland are small: a pilot study in a semiarid basin on the Qinghai-Tibet Plateau
}

\author{
Shuhua Yi ${ }^{1,2}$, Jianjun Chen ${ }^{1,3}$, Yu Qin ${ }^{1}$, and Gaowei Xu${ }^{1,3}$ \\ ${ }^{1}$ State Key Laboratory of Cryosphere Sciences, Cold and Arid Regions Environmental and Engineering Research \\ Institute, Chinese Academy of Sciences, 320 Donggang West Road, Lanzhou 730000, China \\ ${ }^{2}$ School of Geographic Sciences, Nantong University, 999 Tongjing Road, Nantong 226007, China \\ ${ }^{3}$ University of Chinese Academy of Sciences, No.19A Yuquan Road, Beijing 100049, China
}

Correspondence to: Shuhua Yi (yis@1zb.ac.cn)

Received: 26 April 2016 - Published in Biogeosciences Discuss.: 15 June 2016

Revised: 6 October 2016 - Accepted: 9 November 2016 - Published: 23 November 2016

\begin{abstract}
There is considerable controversy about the effects of plateau pika (Ochotona curzoniae, hereafter pika) on alpine grassland on the Qinghai-Tibet Plateau (QTP). On the one hand, pika is considered a keystone species. On the other hand, it is being poisoned. Although significant efforts have been made to study the effects of pika at a quadrat scale $\left(\sim \mathrm{m}^{2}\right)$, our knowledge about its distribution and effects at a larger scale is very limited. In this study, we investigated the direct effects, i.e., burying and grazing, of pika by upscaling field sampling at a quadrat scale to a plot scale $\left(\sim 1000 \mathrm{~m}^{2}\right)$ by aerial photographing. Altogether 168 plots were set on four different types of alpine grassland in a semiarid basin on the QTP. Results showed that (1) the effects of pika pile burying on the reduction of vegetation cover, biomass, soil carbon, and nitrogen were less than $10 \%$, which was much smaller than the effects of bald patches; and (2) pika consumed $8-21 \%$ of annual net primary production of grassland. We concluded that the direct burying and grazing effects of pika on alpine grassland were minor in this region. The quadcopter is an efficient and economic tool for longterm repeated monitoring over large regions for further understanding the role of pika.
\end{abstract}

\section{Introduction}

Alpine grassland is important for animal husbandry and occupies about two-thirds of the total area of the Qinghai-Tibet Plateau (QTP), but about one-third of this resource has degraded over the last few decades (Li et al., 2011). In addition to overgrazing (Zhang et al., 2014), climate warming, and permafrost degradation (Wang et al., 2008; Yi et al., 2011), small mammals, especially plateau pika (Ochotona curzoniae), are considered an important cause of grassland degradation.

Plateau pika (hereafter pika), a small lagomorph, is believed to be adversely affecting alpine grassland by consuming biomass, destroying the sod layer, burying vegetation with excavated soil, and expediting carbon dioxide emission (Qin et al., 2015a). The bald patches created by pika activity may increase in size over time because of erosion by wind and/or water (Wei et al., 2007). According to Shang and Long (2007), 16-54 \% of degraded grassland is severely degraded, referred to as the "black soil patch", half of which is caused by pika ( $\mathrm{Li}$ and Sun, 2009). For this reason, local government considers pika a pest of alpine grassland and has initiated campaigns to eradicate it since 1958 (Wilson and Smith, 2014). Conversely, pika is believed to benefit alpine grassland by increasing infiltration, decreasing runoff (Wilson and Smith, 2014), and increasing moisture and carbon content ( $\mathrm{Li}$ and Zhang, 2006) of the top soil (up to a depth of $10 \mathrm{~cm}$ ). Pika is also a keystone species on the QTP (Smith and Foggin, 1999; Lai and Smith, 2003). Some au- 

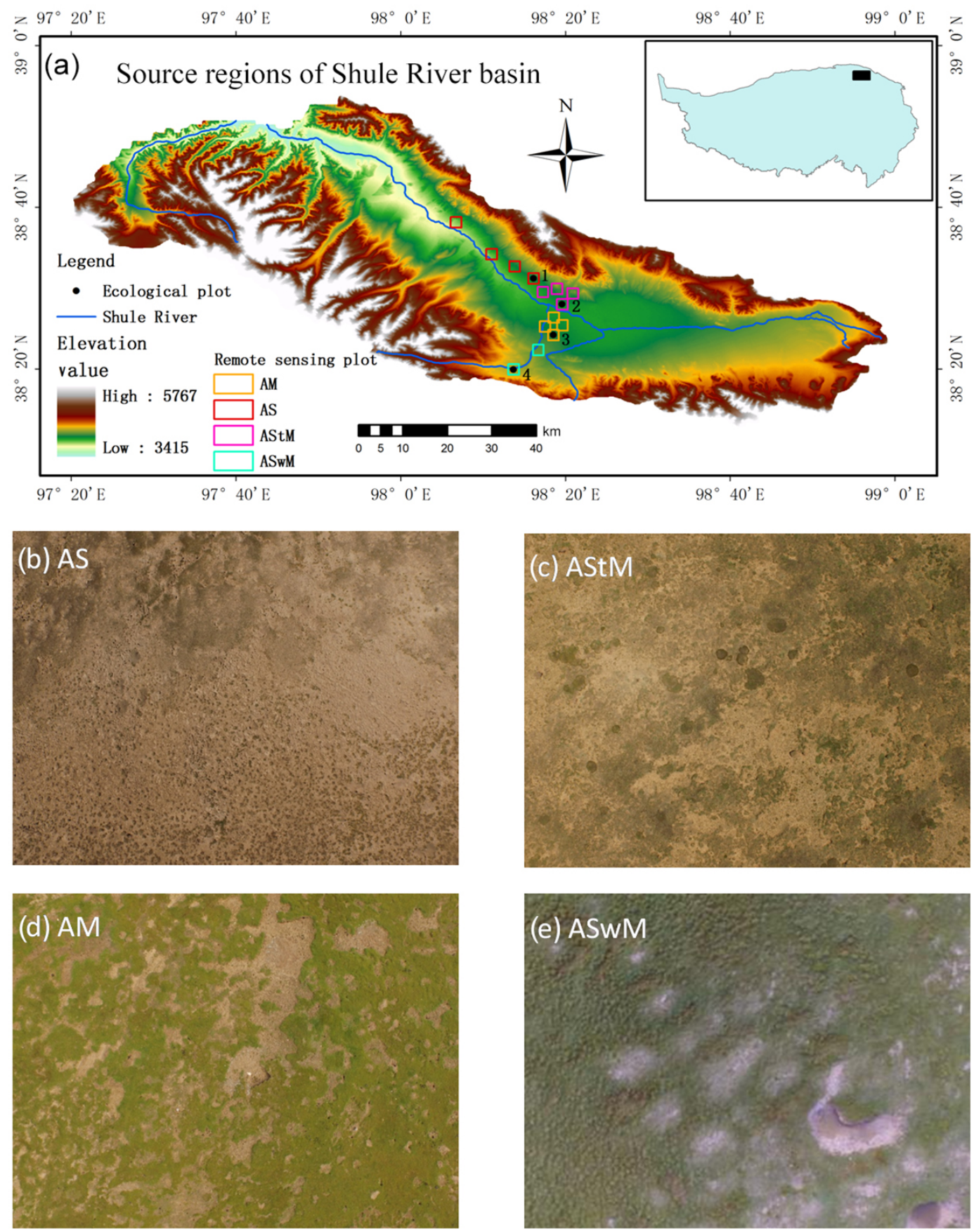

Figure 1. (a) Source region of the Shule River basin and its location in the Qinghai-Tibet Plateau. The rectangles indicate the locations of autopilot flights (each with 12 way points), 1-4 indicate the location of field sampling on each type of grassland; (b)-(e) show aerial photographs of four types of alpine grasslands (AS: alpine steppe; AStM: alpine steppe meadow; AM: alpine meadow; and ASwM: alpine swamp meadow) investigated in this study. Each photograph covers $\sim 35 \mathrm{~m} \times 26 \mathrm{~m}$ ground area.

thors have suggested that pika is an indicator rather than a cause of grassland degradation; pika population increases quickly only after the grassland has already degraded (Harris, 2010; Wangdwei et al., 2013).

Although the role of pika in the alpine grassland ecosystem is receiving more and more attention, there have been few quantitative studies at plot scale (e.g., $\sim 1000 \mathrm{~m}^{2}$, Guo et al., 2012; Wangdwei et al., 2013). Typically, studies on pika effects compare vegetation and soil characteristics and carbon fluxes at a quadrat scale $\left(\sim \mathrm{m}^{2}\right)$ among plots with different number densities of pika burrows (Guo et al., 2012; Li and Zhang, 2006; Liu et al., 2013; Wei et al., 2007; Wilson 
Table 1. The latitude, longitude, and elevation of four different types of alpine grassland and the dominant species on different surface types of each grassland.

\begin{tabular}{|c|c|c|c|c|}
\hline $\begin{array}{l}\text { Grassland } \\
\text { type }\end{array}$ & $\begin{array}{l}\text { Latitude, } \\
\text { longitude, } \\
\text { elevation }\end{array}$ & Vegetation patch & Bald patch & Old pika pile \\
\hline $\begin{array}{l}\text { Alpine steppe } \\
\text { (AS) }\end{array}$ & $\begin{array}{l}38^{\circ} 38^{\prime} 05.4^{\prime \prime} \\
98^{\circ} 06^{\prime} 41.7^{\prime \prime} \\
3768 \mathrm{~m}\end{array}$ & $\begin{array}{l}\text { Stipa purpurea, } \\
\text { Less., Artemisia minor }\end{array}$ & $\begin{array}{l}\text { Heteropappus hispidus (Thunb.), } \\
\text { Saussurea arenaria Maxim. }\end{array}$ & $\begin{array}{l}\text { Potentilla bifurca Linn., } \\
\text { Saussurea arenaria Maxim. }\end{array}$ \\
\hline $\begin{array}{l}\text { Alpine steppe } \\
\text { meadow (AStM) }\end{array}$ & $\begin{array}{l}38^{\circ} 28^{\prime} 34.6^{\prime \prime} \\
98^{\circ} 19^{\prime} 22.8^{\prime \prime} \\
3886 \mathrm{~m}\end{array}$ & $\begin{array}{l}\text { Carex moorcroftii, } \\
\text { Stipa purpurea }\end{array}$ & $\begin{array}{l}\text { Ajania tenuifolia, } \\
\text { Potentilla bifurca Linn. }\end{array}$ & $\begin{array}{l}\text { Potentilla bifurca Linn., } \\
\text { Saussurea arenaria Maxim }\end{array}$ \\
\hline $\begin{array}{l}\text { Alpine meadow } \\
\text { (AM) }\end{array}$ & $\begin{array}{l}38^{\circ} 25^{\prime} 15.2^{\prime \prime} \\
98^{\circ} 18^{\prime} 30.4^{\prime \prime} \\
3897 \mathrm{~m}\end{array}$ & $\begin{array}{l}\text { Kobresia capillifolia, } \\
\text { Carex moorcroftii }\end{array}$ & $\begin{array}{l}\text { Glaux maritima Linn., } \\
\text { Polygonum sibiricum Laxm. }\end{array}$ & $\begin{array}{l}\text { Aster tataricus L.f., } \\
\text { Polygonum sibiricum Laxm. }\end{array}$ \\
\hline $\begin{array}{l}\text { Alpine swamp } \\
\text { meadow (ASwM) }\end{array}$ & $\begin{array}{l}38^{\circ} 19^{\prime} 56.2^{\prime \prime} \\
98^{\circ} 13^{\prime} 35.1^{\prime \prime} \\
4043 \mathrm{~m}\end{array}$ & $\begin{array}{l}\text { Kobresia pygmaea, } \\
\text { Kobresia humilis }\end{array}$ & $\begin{array}{l}\text { Carex atrofusca Schkuh., } \\
\text { Glaux maritima Linn. }\end{array}$ & $\begin{array}{l}\text { Polygonum sibiricum Laxm., } \\
\text { Veronica didyma Tenore. }\end{array}$ \\
\hline
\end{tabular}

and Smith, 2014). For example, Liu et al. (2013) investigated the role of pika in alpine steppe meadows by studying eight plots with pika burrow exit numbers varying from 0 to 76 burrow exits per $100 \mathrm{~m}^{-2}$ and found that a higher density of pika burrow exits was associated with lower net ecosystem exchanges, above-ground biomass, and number of species. There are different levels of heterogeneity on grassland surfaces. For example, Wei et al. (2007) classified the grassland surface into six types: (1) mound height $>10 \mathrm{~cm}$, (2) mound height between 0 and $10 \mathrm{~cm}$, (3) erosion pit between 0 and $5 \mathrm{~cm}$, (4) erosion pit between 5 and $10 \mathrm{~cm}$, (5) erosion pit $>10 \mathrm{~cm}$, and (6) undisturbed. It is critical that measurements taken at a quadrat scale be converted to a plot scale in order to properly quantify the role of pika. However, it is hard and inefficient to walk the ground and count the number of burrow exits or pika piles in situ for a large number of plots (e.g., Liu et al., 2013), not to mention quantifying the area fractions in each plot. Therefore, only a few studies have quantified the effects of pika on alpine grassland at plot scale.

Lightweight unmanned aerial vehicles (UAVs) have developed rapidly due to miniaturization and low cost of various sensors and embedded computers (Salami et al., 2014). UAVs have recently become a popular platform at a low cost for high-precision photography and other applications. Photography with centimeter-level resolution can be achieved with this widely used camera (Colomina and Molina, 2014). In this study, we applied a UAV with a camera to take aerial photos and aimed to (1) test whether pika burrow exit and pile information can be retrieved from aerial photographs at a plot scale, (2) upscale the measurements of biomass, soil carbon, and nitrogen measured at quadrat scale to plot scale and quantitatively assess the burying and grazing effects of pika.

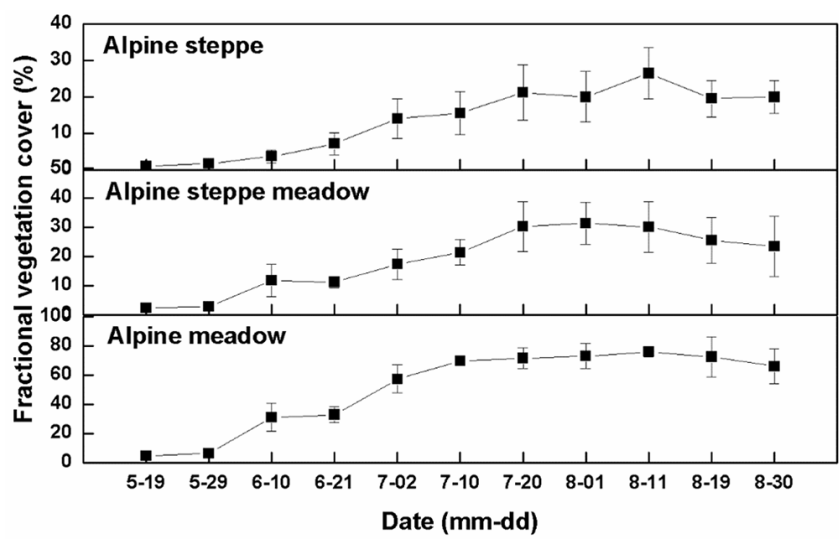

Figure 2. Seasonal variations in fractional vegetation cover during 19 May-30 August 2012 on alpine steppe, alpine steppe meadow, and alpine meadow grasslands of the Shule River basin.

\section{Methodology}

\subsection{Study area and field work}

The study area is located in the source region of the Shule River basin in the Qilian Mountains at the northeastern edge of the QTP, China (Fig. 1a). The area has an arid continental climate. The average annual air temperature and precipitation are about $-4.0^{\circ} \mathrm{C}$ and $200-400 \mathrm{~mm}$, respectively (Chang et al., 2016). There are four typical types of alpine grassland in the study area: alpine steppe (AS), alpine steppe meadow (AStM), alpine meadow (AM), and alpine swamp meadow (ASwM; Fig. 1b-e). The soil moisture ranges from dry in AS grassland to wet in ASwM grassland (Qin et al., 2014). Accordingly, the dominant species was Stipa purpurea in AS 


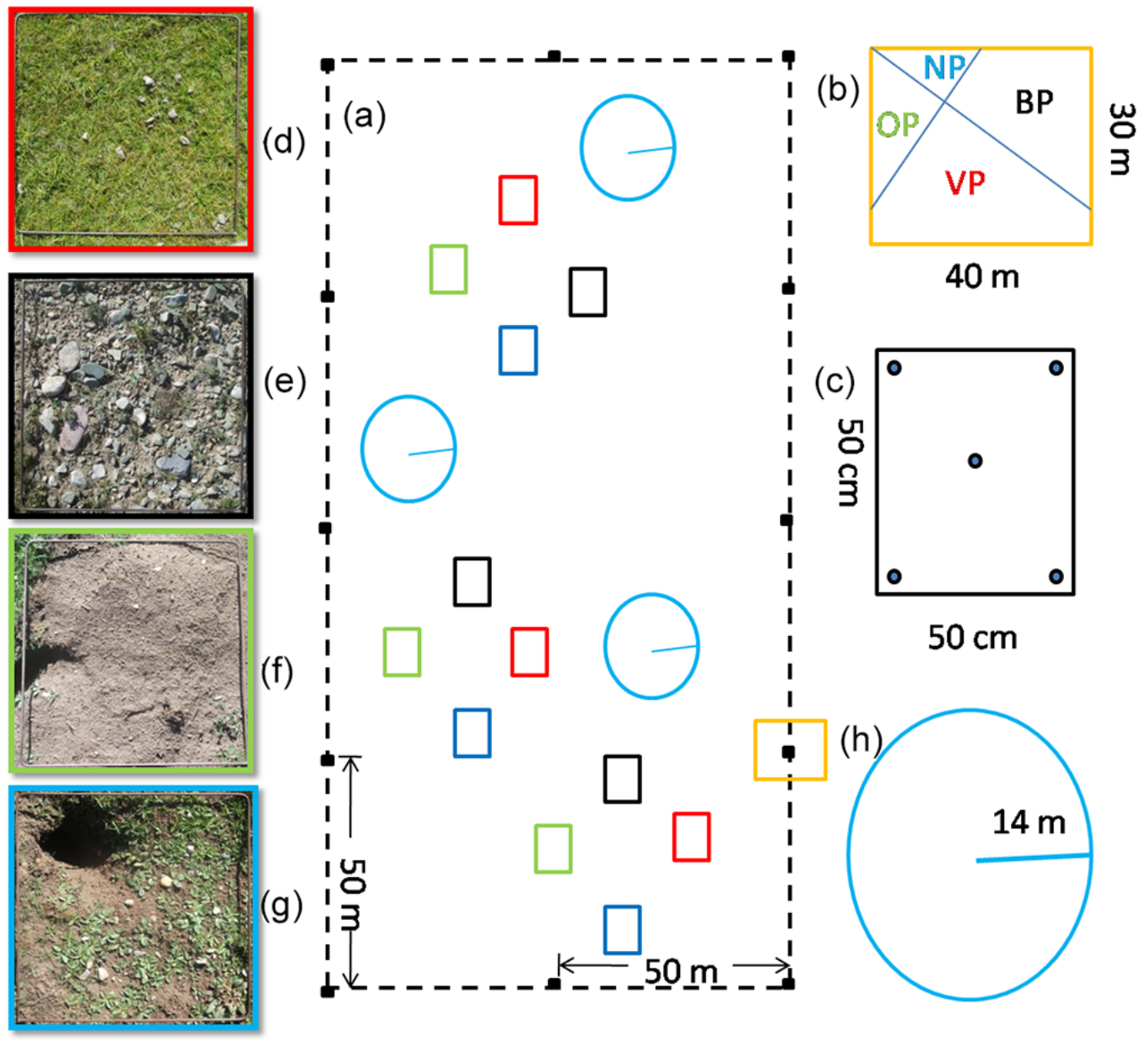

Figure 3. (a) Diagram of ground samples and aerial photographs; (b) aerial photograph on one of 12 way points (solid black rectangles in a), each photo covers $\sim 35 \mathrm{~m}$ by $26 \mathrm{~m}$ of ground area and was analyzed to have four parts, i.e., VP (vegetation patch), BP (bald patch), NP (new pika pile), and OP (old pika pile); (c) ground sample quadrat with $50 \mathrm{~cm}$ by $50 \mathrm{~cm}$ for vegetation cover, soil carbon, and nitrogen (open rectangles in a) with red for vegetation patch (d), black for bald patch (e), green for new pika pile (f), and blue for old pika pile (g); and (h) a circular plot with a radius of $14 \mathrm{~m}$ for counting pika piles and pikas.

grassland and Kobresia pygmaea in ASwM grassland (Table 1). We conducted field studies with field sampling and aerial photographing. We set up three $30 \mathrm{~m} \times 30 \mathrm{~m}$ plots in each of four types of grassland in 2012, and we set up nine $50 \mathrm{~cm} \times 50 \mathrm{~cm}$ quadrats evenly in each plot. We took a photo on each quadrat every 10 days from 19 May to 30 August 2012 at a height of $1.4 \mathrm{~m}$. The protocol of measurement and estimation of fractional vegetation cover can be found in Sect. 2.2 and 2.4, respectively. Vegetation cover usually peaks at the end of July and beginning of August (Fig. 2).

\subsection{Field sampling}

For each grassland type, we delineated four surface types: vegetation patch, new pika pile (with loose soil and a burrow exit nearby), old pika pile, and bald patch (Fig. 3d-g). At the end of July 2014, we randomly set up three quadrats with iron frames measuring $50 \mathrm{~cm} \times 50 \mathrm{~cm}$ on each surface type in each type of grassland (Fig. 3a). For new and old pika pile surface types (Fig. $3 \mathrm{f}$ and $\mathrm{g}$ ), the iron frames were placed so as to cover vegetation as little as possible. We took one picture of each quadrat with an ordinary digital camera (1000 megapixels, Fujifilm, Japan) held vertically at a height of $\sim 1.4 \mathrm{~m}$ (Fig. $3 \mathrm{~d}-\mathrm{g}$ ). Five soil cores were collected on each quadrat with a stainless auger $(5 \mathrm{~cm}$ in diameter) down to $40 \mathrm{~cm}$ (Fig. 3c) and bulked as one composite sample. Three replicates on each surface type of each grassland type were sampled.

At the beginning of August 2015, we set three round plots with radius of $14 \mathrm{~m}$ around the sampling place in each type of grassland (Fig. 3h). Distance between plots was over $50 \mathrm{~m}$. We covered all burrow exits with soil within each plot. The number of burrow exits that were opened was counted after $72 \mathrm{~h}$. Then we put a trap on each of the opened burrow exits, and checked whether a pika was caught after $48 \mathrm{~h}$. The exper- 

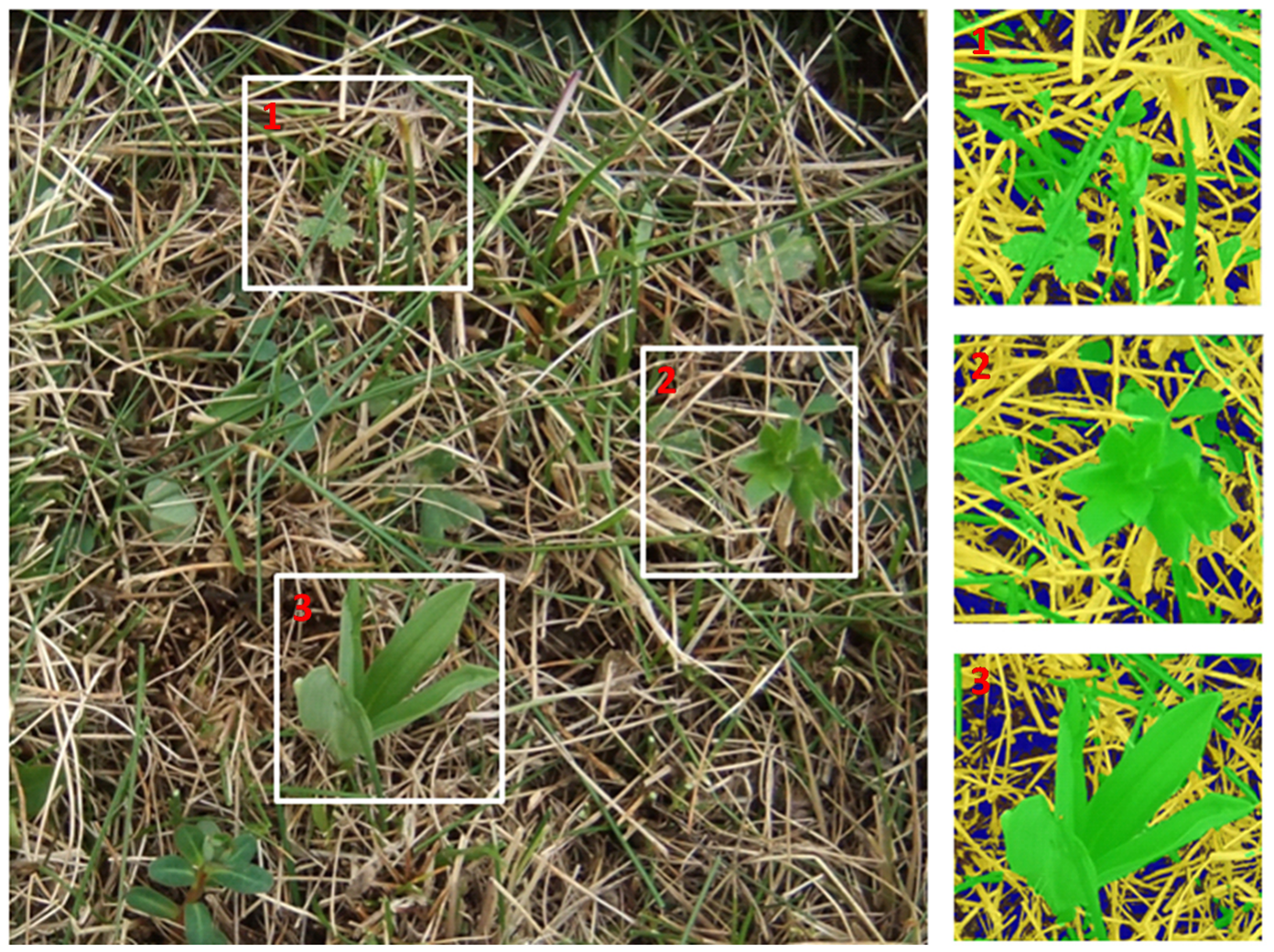

Figure 4. A photo taken on the ground (left) and three examples (white rectangles) of green vegetation (green) classification (1-3 on the right).

iment protocol was approved by the Department of Qinghai Prataculture (due to the small size of experiment, only oral approval was granted).

\subsection{Aerial photographing}

At the beginning of August 2015, we selected 14 locations, among which four, four, four, and two locations were in AS, AStM, AM, and ASwM grasslands, respectively. (Fig. 1). There were three, two, zero, and zero locations on the alluvial terrace and one, two, two, and two locations on the river terrace. All locations are generally flat with a slope of less than $4^{\circ}$. Grasslands of these locations are used for grazing during migration between settlement and mountain areas in MayJune and September-October. Pikas of these locations are not poisoned. One location in each type of grassland was over the above-mentioned sampling plots and quadrats (Fig. 3a). Using software development kits, the DJI drone (Phantom 3 Professional, DJI Innovation Company, China) took a photo at a height of $20 \mathrm{~m}$ with the camera looking down vertically (Yi, 2016). The drone was set on autopilot to visit the 12 preset way points at each location. Altogether 168 aerial photos were taken. The Phantom 3 Professional is a lightweight (about $1280 \mathrm{~g}$ including battery and propellers) four-wheel drone. It is equipped with an autopilot system with $0.5 \mathrm{~m}$ vertical accuracy and $2.0 \mathrm{~m}$ horizontal accuracy. It is integrated with a Sony EXMOR sensor (maximum image size is $4000 \times 3000$ ) and a three-axis gimbal. Each aerial photo covers roughly $35 \mathrm{~m} \times 26 \mathrm{~m}$ (Fig. $3 \mathrm{a}$ and b), and each pixel covers roughly $1 \mathrm{~cm}^{2}$ of ground area, when the photo is taken at a height of $20 \mathrm{~m}$.

\subsection{Image analysis}

For those images taken on the ground, we selected the part of the image within the iron frame and retrieved green fractional vegetation cover (GFVC) using a threshold method based on excess green index $(E G I=2 G-R-B$; with $R, G, B$ being red, green, and blue bands, respectively) of each pixel. More specifically, to calculate GFVC we (1) provided an initial value of EGI threshold and compared it with each pixel; (2) if the EGI of a pixel was greater than the threshold, the pixel was considered a vegetation pixel and assigned a green color, otherwise it was considered a non-vegetation pixel and assigned a yellow color; and (3) compared the classified image with the original picture. Steps (1) through (3) were iterated to adjust the threshold value until the vegetation shapes in the classified image fit those of the original picture (Fig. 4). Finally, we calculated GFVC by dividing the number of vegetation pixels into the total number of pixels. 


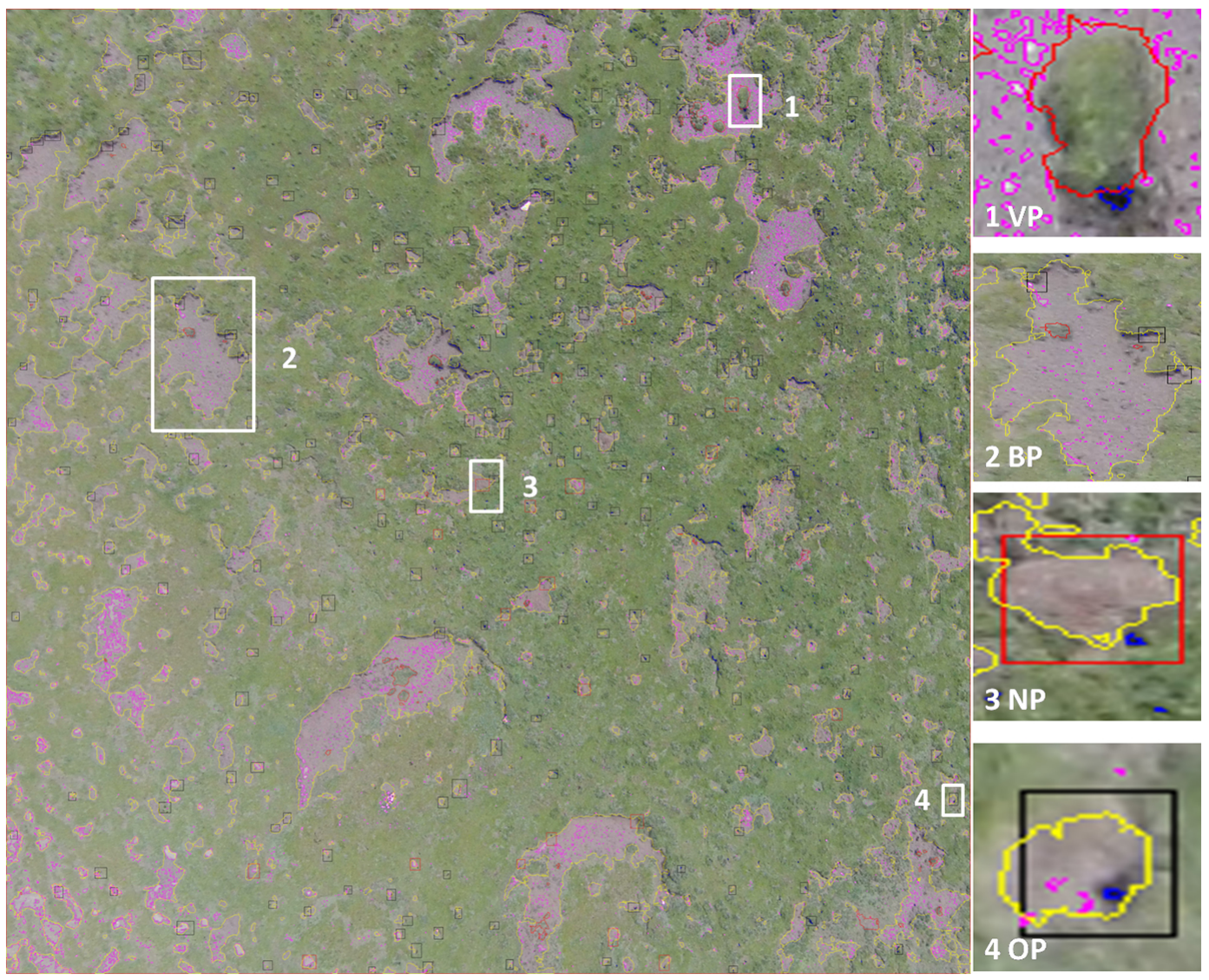

Figure 5. An aerial photo and contours of vegetation patch (red curves, VP), bald patch (yellow curves, BP), new pika pile (red rectangles, $\mathrm{NP}$ ), old pika pile (black rectangles, OP), and enlarged examples on the right for each type. Pink contour indicates gravel.

For pictures taken from the air (Fig. 5), the new and old pika piles were marked manually with rectangles so as to include as little intact vegetation as possible (Fig. 5). We plotted the contours of the vegetation and bald patches using OpenCV Library where we (1) adjusted the EGI value until its contours fit well with the shape of the vegetation and bald patches (Fig. 5), (2) calculated the area in each contour in units of pixel using OpenCV Library, and (3) subtracted the number of vegetation and non-vegetation pixels of new and old pika piles from the vegetation and bald patch contours. To exclude very small patches, we only considered the patches with an area greater than $10 \mathrm{~cm}^{2}$. The area fractions of vegetation and bald patches and new and old pika piles were then calculated by dividing the number of pixels in each surface type by the total number of pixels (see Fig. 3b).

It is worth mentioning that no true FVC (fractional vegetation cover) of grassland at both quadrat and plot scale exists. Results from supervised classification have usually been used as "true" FVC values. For example, supervised classification using WinCAM software was used in Yi et al. (2011), Ren et al. (2014), and Zhou et al. (2015). Yi et al. (2011) found that widely used visual estimation had large variations among different estimators, while WinCAM classification was time consuming. Ren et al. (2014) found that trial-and-error threshold-based estimation was comparable to that of WinCAM classification and was more efficient than WinCAM. In addition to the EGI-based threshold method, we also tried green relative vegetation index $(\mathrm{GRVI}=(\mathrm{G}-\mathrm{R}) /(\mathrm{G}+\mathrm{R})$; Motohka et al., 2010). We did not try the normalized difference vegetation index $(\mathrm{NDVI}=(\mathrm{NIR}-\mathrm{R}) /(\mathrm{NIR}+\mathrm{R})$, where NIR is near infrared band), due to lack of NIR band in a common camera.

\subsection{Laboratory analysis}

Soil samples were processed in the following steps: (1) airdried in natural conditions avoiding direct sunshine; (2) the gravel, $>2 \mathrm{~mm}$ in size, was sieved, separated, and weighted by an electronic balance ( $0.01 \mathrm{~g})$; and (3) the remaining soil samples with a diameter less than $2 \mathrm{~mm}$ were ground to pass through a $0.25 \mathrm{~mm}$ sieve and were then sent to Lanzhou University for analysis of soil organic carbon (SOC) and total nitrogen (TN) concentration. A detailed description of the analysis methods for SOC and TN can be found in Qin et al. (2014). 

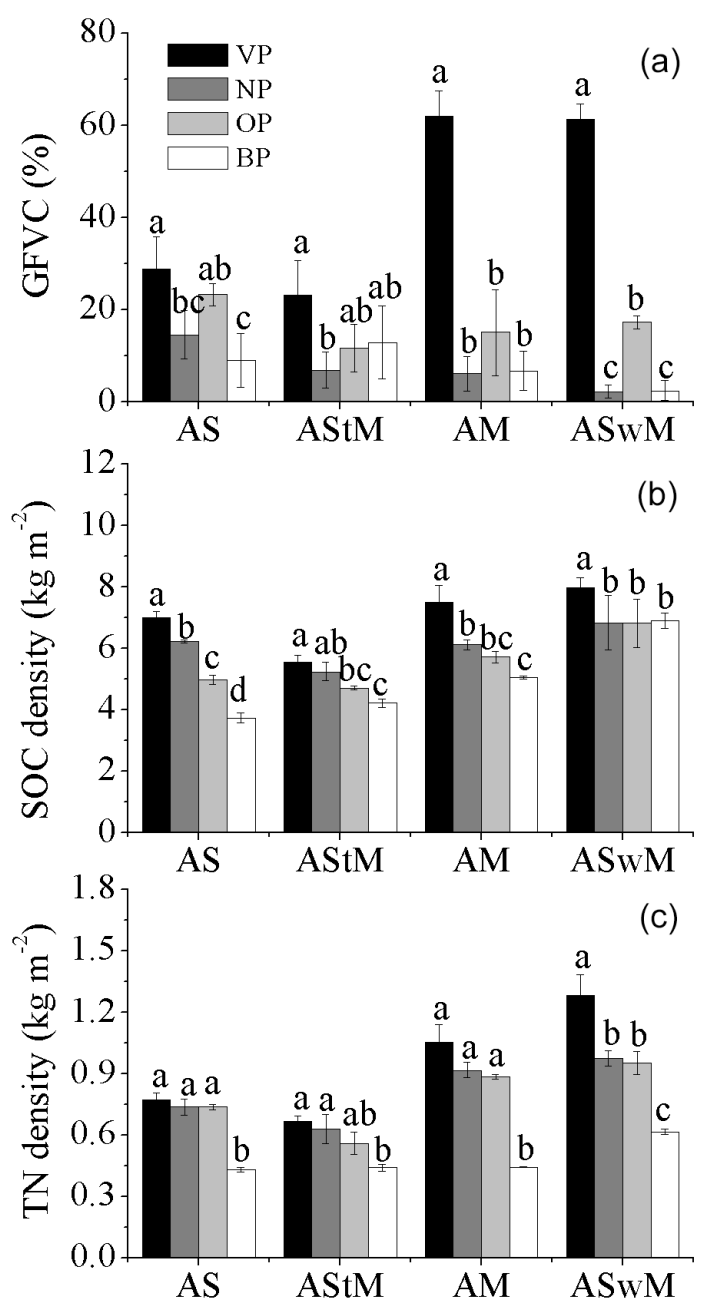

Figure 6. Green fractional vegetation cover (GFVC, \%; a) soil organic carbon density (SOC, $\left.\mathrm{kg} \mathrm{m}^{-2} ; \mathbf{b}\right)$ and total soil nitrogen density $\left(\mathrm{TN}, \mathrm{kg} \mathrm{m}^{-2}\right.$; c) of vegetation patch (VP), new pika pile (NP), old pika pile (OP), and bald patch (BP) at a quadrat scale of four types of alpine grasslands (see Fig. 1). Error bar indicates \pm standard deviation and different letters above the error bar indicate significant differences among surface types $(p<0.05)$.

\subsection{Data analysis}

\subsubsection{Plot scale biomass, soil organic carbon, and total nitrogen}

Based on the relationship between GFVC and above-ground biomass (AGB) at a quadrat scale, established using datasets of the same study area (Qin et al., 2014), we calculated AGB $\left(\mathrm{kg} \mathrm{ha}^{-1}\right)=21.6 \times$ GFVC for each surface type. For each plot, we calculated the overall AGB with the following equation:

$$
\begin{aligned}
\mathrm{AGB}_{\mathrm{plot}} & =\mathrm{AGB}_{\mathrm{np}} f_{\mathrm{np}}+\mathrm{AGB}_{\mathrm{op}} f_{\mathrm{op}} \\
& +\mathrm{AGB}_{\mathrm{bp}} f_{\mathrm{bp}}+\mathrm{AGB}_{\mathrm{vp}} f_{\mathrm{vp}}
\end{aligned}
$$

where plot, np, op, bp, and vp represent plot, new pika pile, old pika pile, bald patches, and vegetation patches, respectively; $f$ represents area fraction $(\%)$ of each surface type. The SOC and TN at plot scale were then calculated in a similar way to that of AGB.

We defined the effect of each surface type ( $\left.E_{\text {type }}\right)$ on AGB reduction of grassland as

$E_{\mathrm{type}, \mathrm{agb}}=\frac{\left(\mathrm{AGB}_{\mathrm{type}}-\mathrm{AGB}_{\mathrm{vp}}\right) f_{\mathrm{type}}}{\sum\left[\left(\mathrm{AGB}_{\mathrm{type}}-\mathrm{AGB}_{\mathrm{vp}}\right) f_{\mathrm{type}}\right]} \times 100$,

where $f_{\text {type }}$ represents the area fraction of a surface type in a plot (\%), $\sum$ means the sum. For the vegetation patch surface type, and $E_{\text {type }}$ equals zero and has no effect on AGB reduction. The higher the value of $E_{\text {type,agb }}$, the higher the effect of a surface type on plot-scale AGB reduction. The effects on SOC and TN reduction were calculated in a similar way. The burying effects from pika piles were calculated as the sum of $E_{\mathrm{np}}$ and $E_{\mathrm{op}}$.

\subsubsection{Plot-scale pika number and grazing effects}

Two ratios were used in calculating the number of pika from aerial photos at plot scale. First was the ratio (r1) between the number of in-use burrow exits and the total number of burrow exits, and the second was the ratio (r2) between the number of pikas caught and the number of in-use burrow exits, both of which were developed using field data for each grassland type (Fig. 3h). We then calculated the number of pikas in a plot covered by each aerial photo (Fig. 3b) with these two ratios and the total number of pika piles delineated from each aerial photo (Fig. 5; Eq. 3).

$N_{\text {pika }}=N_{\text {pile }} \times \mathrm{r} 1 \times \mathrm{r} 2$,

where $N_{\text {pika }}$ and $N_{\text {pile }}$ are the number of pikas and the number of total pika piles in a hectare, respectively.

Each pika consumes $\sim 8.06 \mathrm{~kg}$ of grass dry matter per year (Hou, 1995; Eq. 4). Pika consumes above-ground biomass more than root systems (Sun et al., 2016). The annual primary production of grassland roughly equals the peak time of above-ground biomass (AGB plot; Scurlock et al., 2002). Finally, we estimated the effects of direct graze consumption of pika $\left(E_{\text {graze }}, \%\right)$ in a plot (Eq. 5).

$$
\begin{aligned}
\mathrm{AGB}_{\text {pika }} & =N_{\text {pika }} \times 8.06 \\
\mathrm{E}_{\text {graze }} & =\frac{\mathrm{AGB}_{\text {pika }}}{\mathrm{AGB}_{\text {plot }}} \times 100
\end{aligned}
$$

$\mathrm{AGB}_{\text {pika }}$ is the biomass consumed by pika $\left(\mathrm{kg} \mathrm{ha}^{-1}\right)$.

The data were presented as mean \pm standard deviation. Statistical analyses were performed using the SPSS 17.0 statistical software package (SPSS Inc., Chicago, IL, USA). One-way analysis of variance (ANOVA) and a multicomparison of a least significant difference (LSD) test were used to distinguish between differences at the $p=0.05$ level. 

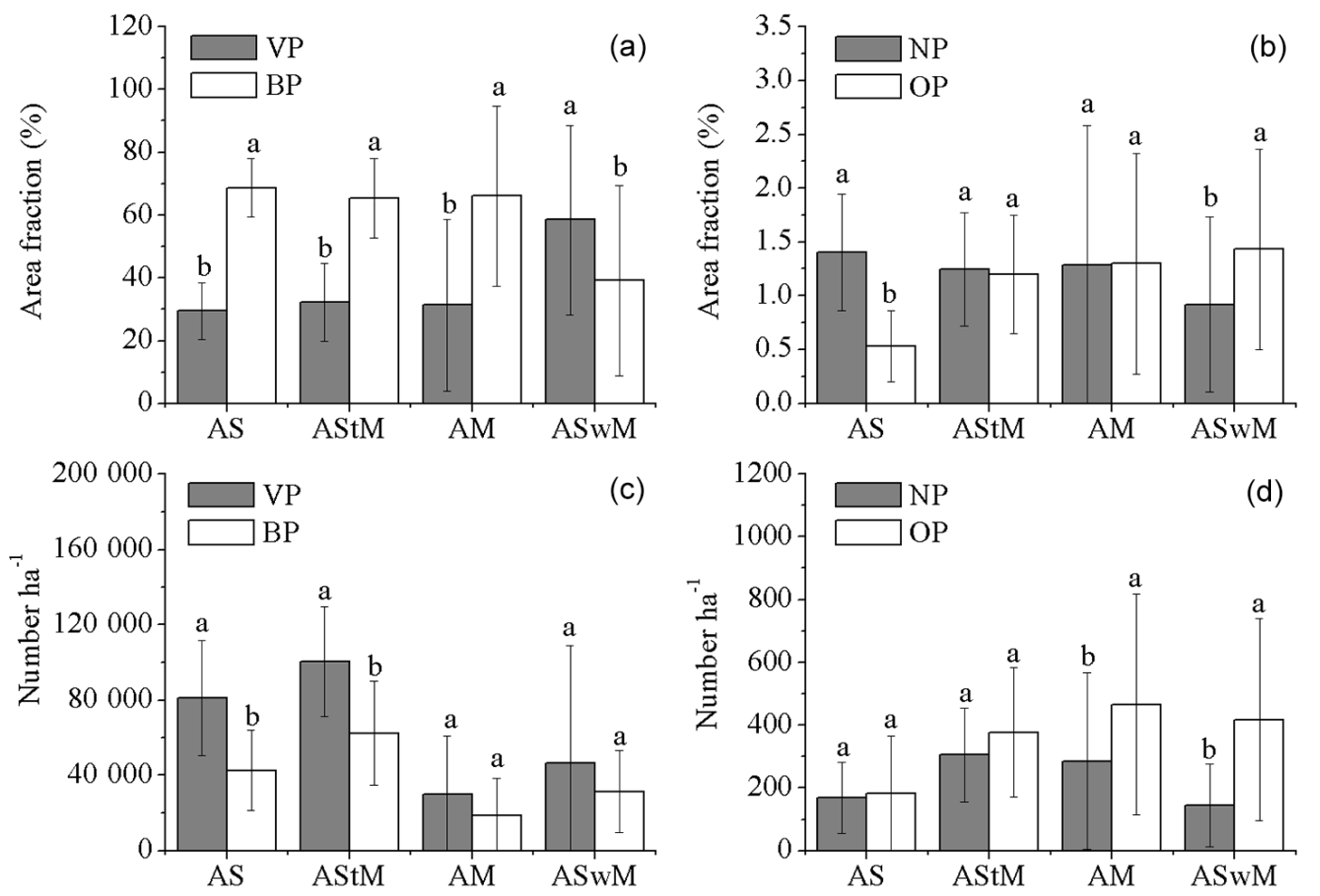

Figure 7. Area fraction (\%) and number $\left(\mathrm{ha}^{-1}\right)$ of vegetation patch (VP), new pika pile (NP), old pika pile (OP), and bald patch (BP) at a plot scale of four types of alpine grasslands (see Fig. 1). Error bar indicates \pm standard deviation and different letters above the error bar indicate significant differences between VP and BP or between NP and OP $(p<0.05)$.

\section{Results}

\subsection{Quadrat scale characteristics}

The GFVCs derived using thresholds of EGI and GRVI were similar, with differences less than $1 \%$ (Figure not shown here). Therefore, in the following part, we only presented results based on the EGI threshold.

The GFVCs of the vegetation patches were greater than $60 \%$ for both AM and ASwM grasslands, while those of AS and AStM grasslands were less than $30 \%$ (Fig. 6a). The GFVC of vegetation patches was significantly greater than that of other surface types for most of the grasslands $(p<0.05)$. Because some vegetation was included in the $50 \times 50 \mathrm{~cm}$ iron frame, the GFVC of new pika piles was not zero, but usually less than $10 \%$. Vegetation also grew on the piles, so the GFVC of old pika piles was usually greater than that of new pika piles. Bald patch GFVC was similar to that of new pika piles.

The SOC-TN densities of the $40 \mathrm{~cm}$ soil column ranged between $3.5--0.45$ and $8.0--1.2 \mathrm{~kg} \mathrm{~m}^{-2}$ (Fig. $6 \mathrm{~b}$ and c). Both SOC and TN densities under vegetation patches were significantly greater than those under bald patches $(p<0.05)$. SOCs under vegetation patches of three out of four grasslands were significantly greater than those under new and old pika piles (Fig. 6b). TNs under vegetation patches were only significantly greater than those of new and old pika piles on the ASwM grassland (Fig. 6c). Species in vegetation patches were dominated by palatable species, while lownutrient forbs were common in bald patches and old pika piles on all four different grasslands (Table 1).

\subsection{Area fractions and numbers of surface types at plot scale}

Except for the ASwM grassland, the mean area fractions of vegetation patches were about $30 \%$ and were significantly less than bald patches $(p<0.05$; Fig. 7a). The mean area fractions of new and old pika piles were less than $2 \%$ for all grasslands (Fig. 7b). The mean number of patches of vegetation (bald) patches ranged from $\sim 33000\left(17000 \mathrm{ha}^{-1}\right)$ in AM grassland to $\sim 100000 \mathrm{ha}^{-1}\left(67000 \mathrm{ha}^{-1}\right)$ in AStM grassland (Fig. 7c). The mean number of new and old pika piles ranged from $\sim 130\left(160 \mathrm{ha}^{-1}\right)$ to $\sim 270 \mathrm{ha}^{-1}$ $\left(400 \mathrm{ha}^{-1}\right)$, respectively (Fig. $\left.7 \mathrm{~d}\right)$.

\subsection{Effects of surface types at plot scale}

Due to the large area fractions of bald patches (Fig. 7a) and low vegetation cover (Fig. 6a), the effects of bald patches on reduction of above-ground biomass ranged from $80 \%$ on ASwM grassland to $98 \%$ on AS and AStM grasslands (Fig. 8a). The effects of pika piles were significantly less than 

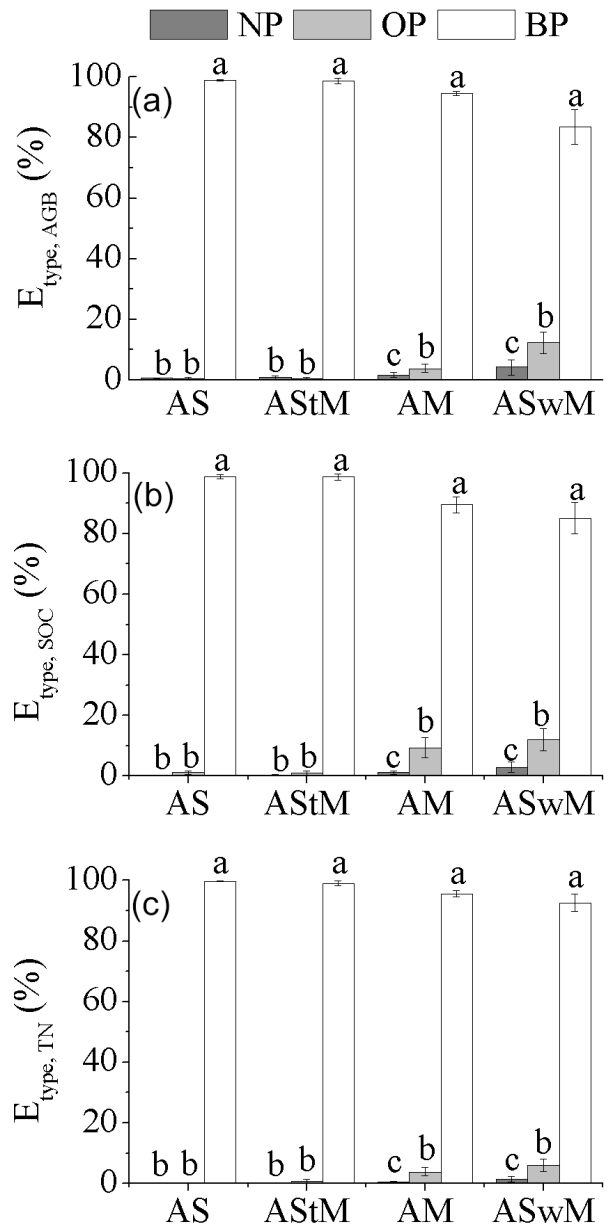

Figure 8. Effects of new pika pile (NP), old pika pile (OP), and bald patch (BP) on reduction of fractional vegetation cover (a), soil carbon density (SOC) (b), and total nitrogen (TN) (c) on four types of alpine grasslands (see Fig. 1). Error bar indicates \pm standard deviation and different letters above the error bar indicate significant differences among different surface types $(p<0.05)$.

that of bald patches. The soil organic carbon and total nitrogen had a similar pattern to that of above-ground biomass (Fig. 8b and c).

\subsection{Grazing effects of pika at plot scale}

The mean ratio between in-use burrow exits and total burrow exits (r1) ranged from 0.22 to 0.42 , and there were no significant differences among different grassland types $(p>=0.05$; Fig. 9a). The mean ratio between number of pikas and inuse burrow exits (r2) ranged from 0.18 on ASwM grassland to 0.4 on AM grassland (Fig. 9b). The r2 of ASwM grassland was significantly less than that of the other grasslands $(p<0.05)$. The mean number of pikas ranged from $27 \mathrm{ha}^{-1}$ to $60 \mathrm{ha}^{-1}$, and there were no significant differences among different types of grasslands ( $p>=0.05$; Fig. 9c). The graze effects of pika on above-ground biomass ranged from 8 to
$21 \%$, with the effects on AStM being significantly greater than those of the other grasslands ( $p<0.05$; Fig. 9d)

\section{Discussion}

\subsection{Burying and grazing effects of pika on grassland}

Previous studies indicated that pika adversely affect alpine grassland directly through (1) burying of vegetation with soil while burrowing and (2) consumption of vegetation in competition with domestic animals for food (Yang and Jiang, 2002). However, our study showed that both new and old pika piles accounted for only a very small area fraction $(<2 \%)$ of the total plot area (Fig. 7b), showing that burying has minimal effects on above-ground biomass, soil carbon, and total nitrogen (Fig. 8). The above-ground biomass at peak growing season is usually used as a surrogate for annual net primary production (Scurlock et al., 2002). Pika only accounted for $21 \%$ of maximum of different types of grassland in two different geomorphologies (Fig. 9d).

Sun et al. (2016) classified study sites into four classes: (1) approximately zero pika density $\left(0-15 \mathrm{ha}^{-1}\right)$, (2) low pika density (15-110 ha $\left.{ }^{-1}\right)$, (3) medium pika density (110 $200 \mathrm{ha}^{-1}$ ), and (4) high pika density (200-300 ha $\left.{ }^{-1}\right)$. Our plots belong to the first two classes (Fig. 9c). Due to different precipitation and temperature conditions, net primary production, soil carbon, and nitrogen exhibits strong spatial heterogeneity (Luo et al., 2004). Therefore, to properly evaluate the direct burying and grazing effects of pika on the QTP, large amounts of plots under different combined conditions of climate and pika densities should be investigated.

\subsection{Effects of pika on bald patches}

There were bald patches of various sizes on the grasslands (see Fig. 5), which played a much more important role than pika piles in reducing vegetation cover, aboveground biomass, soil carbon, and nitrogen at the plot scale (Fig. 8). We retrieved gravel contours using the threshold of $\mathrm{R}+\mathrm{G}+\mathrm{B}$ and determined whether each was in a vegetation or bald patch contour. The number of gravel contours in bald patches was significantly greater than the number in vegetation patches (e.g., Figs. 3e and 5). For example, there was $\sim 80$ gravel $\mathrm{m}^{-2}$ in bald patches and $\sim 5$ gravel $\mathrm{m}^{-2}$ in vegetation patches on the AM grassland (Figure not shown). High amounts of gravel content are not beneficial for nutrient retention and vegetation growth (Qin et al., 2015b): once the fine soil has been eroded, vegetation in a bald patch is slow to recover (Gao et al., 2011).

Wei et al. (2007) suggested that a bald patch developed from a new pika pile through its succession to an old pika pile and further erosion by wind and/or water. Other studies have suggested that a bald patch originates from the collapse of a burrowing tunnel, repeated freeze and thaw processes, trampling during grazing, or some combination of these fac- 

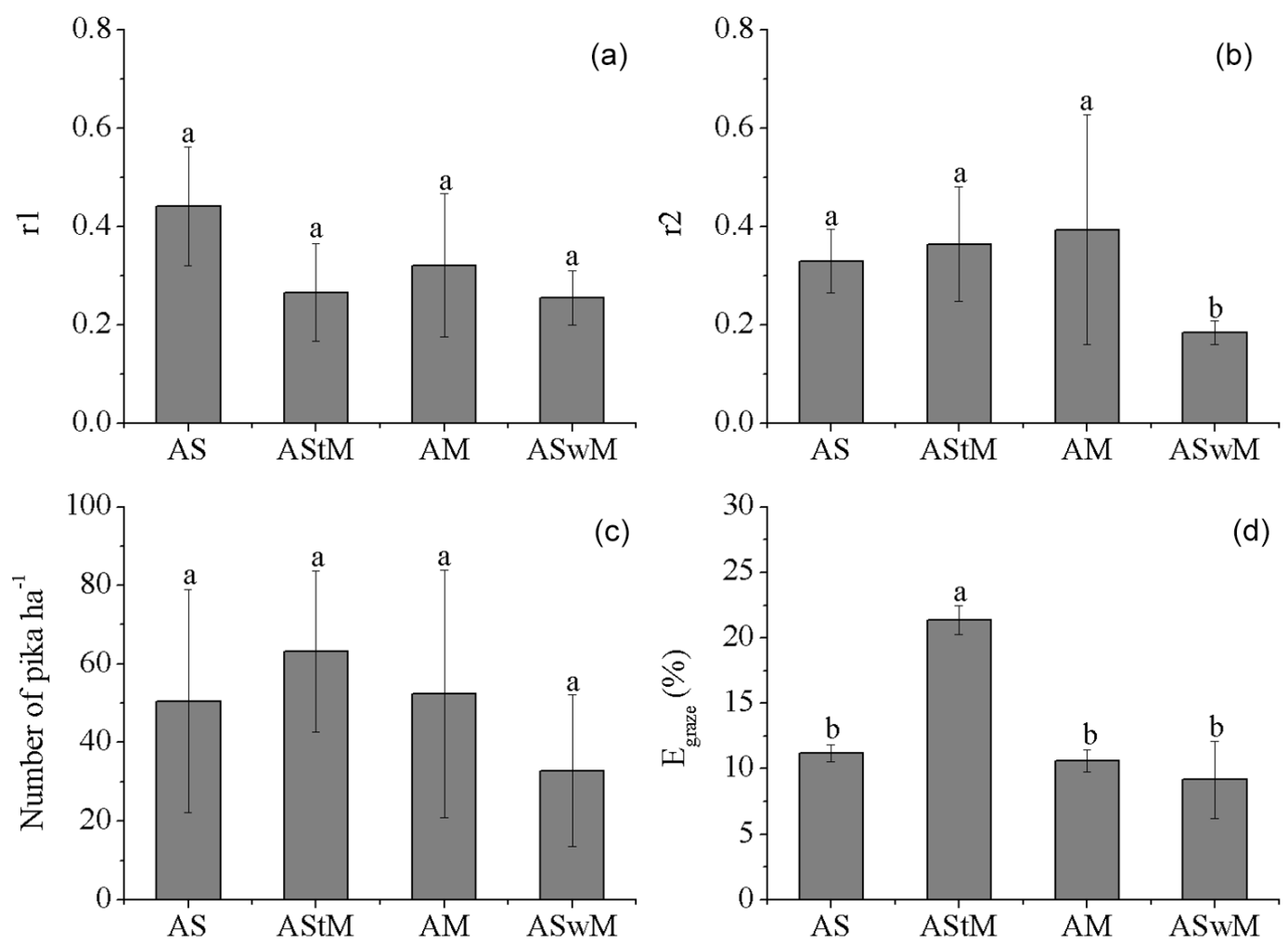

Figure 9. (a) Ratio between in-use burrow exits and total burrow exits (r1); (b) ratio between number of pika and in-use burrow exits (r2), (c) number of pikas $\left(\mathrm{ha}^{-1}\right)$, and (d) effects of pika grazing on above-ground biomass (\%) in four types of alpine grasslands (see Fig. 1). Error bar indicates \pm standard deviation and different letters above the error bar indicate significant differences among different grassland types $(p<0.05)$.

tors (Zhou et al., 2003; Cao et al., 2010). However, none of these suggestions have been supported by field observations (Wilson and Smith, 2014). Therefore, it is critical to perform long-term repeated monitoring studies to determine (1) whether bald patches are developed from pika piles or burrow tunnels, (2) how quickly a bald patch expands, and (3) what the major factors affecting bald patch expansion are.

\subsection{Pros and cons of quadcopter in studying pika effects}

Pika piles or burrow exits and bald patches are too numerous to be quantified easily on ground by humans; they are also too small to be identified by regularly available satellite remote sensing data (Figs. 5 and 7). Quadcopter integrated with a camera has the following advantages in studying pika's effects: (1) large coverage. It can easily cover an area of $\sim 1000 \mathrm{~m}^{2}$ when it is flown at a height of $\sim 20 \mathrm{~m}$. Therefore, aerial photos can be used to better characterize patches of different sizes than photos taken on the ground; (2) high resolution. Each pixel represents an area of $\sim 1 \mathrm{~cm}^{2}$ when the photo is taken at a height of $\sim 20 \mathrm{~m}$, which is good enough for identifying pika piles and bald patches (Fig. 5); (3) high locating accuracy. The distance between the center of an aerial photo and the corresponding preset way point is $\sim 1 \mathrm{~m}$, which makes it feasible for repeated monitoring over the same plots (Yi, submitted); (4) low cost. Each Phantom 3 quadcopter costs about 1000 USD; and (5) high efficiency. In our study, it only took 2 min to fly to 12 preset way points and take photos automatically (Fig. 3a).

Chen et al. (2016) found that the fractional vegetation cover derived from aerial photos had better correlations with satellite normalized difference vegetation index, which is usually used to estimate vegetation biomass (e.g., Gao et al., 2013) than quadrat-scale photos taken on the ground in patchy grassland. It is a non-destructive method of estimating biomass or soil carbon and nitrogen at plot scale with only a few samples taken at quadrat scale. Therefore, it is feasible to deploy a quadcopter to monitor large amounts of plots in alpine grassland on the QTP repeatedly over a long-term range.

However, we do acknowledge that there are some shortcomings of the quadcopter: (1) we cannot assess the role of pika at a species level with the quadcopter. For example, selective grazing behavior of pika can sometimes improve alpine grassland biodiversity (Harris et al., 2016; Zhang et al., 2016), which cannot be upscaled to a plot scale in aerial photos. (2) A quadcopter with a common camera cannot pro- 
vide soil moisture information, while the burrowing activity of pika can improve infiltration and increase soil water content (Wilson and Smith, 2014). Therefore, both aerial surveying with the quadcopter and ground sampling should be used together to investigate the role of pika comprehensively.

\section{Conclusions}

We upscaled the quadrat-scale measurements of vegetation cover, biomass, soil carbon, and nitrogen of four different surface types, i.e., vegetation and bald patches and new and old pika piles, to plot scale using aerial photography. We then assessed the direct burying and grazing effects of pika. We concluded that the direct effects were minor on different types of grasslands in two different geomorphologies. Bald patches have a large impact on the reduction of biomass, soil carbon, and nitrogen, but cannot be directly associated with pika activity at the current stage, which requires long-term repeated monitoring of changes of piles and burrow tunnels created by pika. Our study suggested that it is feasible and efficient to use a quadcopter to monitor large amounts of patchy grassland plots and study the roles of pika.

\section{Data availability}

Data are available upon request.

Acknowledgements. We would like to thank Matthias Peichl of the Swedish University of Agricultural Sciences for his helpful suggestions and comments and Xiaofeng Deng and Tianfeng Wei for helping identify the geomorphology of our study locations using Google Earth. This study was jointly supported by grants from the Chinese National Natural Science Foundation Commission (41422102 and 41501081) and the independent grants from the State Key Laboratory of Cryosphere Sciences (SKLCS-ZZ-2015). No conflict of interest was involved in this study.

Edited by: N. Ohte

Reviewed by: two anonymous referees

\section{References}

Cao, G., Long, R., Zhang, F., Lin, L., Li, Y., and Liang, D... Mechanism of denuded pits developing in degraded alpine Kobresia humilis meadow in the Three Rivers Source Region, Grassland Turf, 30, 16-21, 2010 (in Chinese with English abstract).

Chang, Y., Ding, Y., Zhao, Q., and Zhang, S.: Remote estimation of terrestrial evapotranspiration by Landsat $5 \mathrm{TM}$ and the SEBAL model in cold and high-altitude regions: A case study of the upper reach of the Shule River Basin, China, Hydrol. Process., doi:10.1002/hyp.10854, 2016.

Chen, J., Yi, S., Qin, Y., and Wang, X.: Improving estimates of fractional vegetation cover based on UAV in alpine grassland on the
Qinghai-Tibetan Plateau, Int. J. Remote Sens., 37, 1922-1936, doi:10.1080/01431161.2016.1165884, 2016.

Colomina, I. and Molina, P.: Unmanned aerial systems for photogrammetry and remote sensing: A review, ISPRS J. Photogramm. Remote Sens., 4, 1671-1692, 2014.

Gao, T., Xu, B., Yang, X., Jin, Y., Ma, H., Li, J., and Yu, H.: Using MODIS time series data to estimate aboveground biomass and its spatio-temporal variation in Inner Mongolia's grassland between 2001 and 2011, Int. J. Remote Sens., 34, 7796-7810, 2013.

Gao, Y., Zhong, B., Yue, H., Wu, B., and Cao, S.: A degradation threshold for irreversible loss of soil productivity: a long-term case study in China, J. Appl. Ecol., 48, 1145-1154, 2011.

Guo, Z., Zhou, X., and Hou, Y.: Effect of available burrow densities of plateau pika (Ochotona curzoniae) on soil physicochemical property of the bare land and vegetation land in the QinghaiTibetan Plateau, Acta Ecol. Sin., 32, 104-110, 2012.

Harris, R. B.: Rangeland degradation on the Qinghai-Tibetan plateau: A review of the evidence of its magnitude and causes, J. Arid Environ., 74, 1-12, 2010.

Harris, R. B., Wang, W., Badinqiuying, Smith, A. T., and Band edunah, D. J.: Herbivory and Competition of Tibetan Steppe Vegetation in Winter Pasture: Effects of Livestock Exclosure and Plateau Pika Reduction, PLoS ONE, 10, e0132897, doi:10.1371/journal.pone.0132897, 2016.

Hou, X.: A preliminary study on the effects of eagle- attractingracks on number of Plateau pika population, Qinghai, Pratacul, 4, 27-30, 1995 (in Chinese).

Lai, C. H. and Smith, A. T.: Keystone status of plateau pikas (Ochotona curzoniae): effect of control on biodiversity of native birds, Biodivers. Conserv., 12, 1901-1912, 2003.

Li, S. and Sun, X.: Research about analysis of the causes of ecological degradation of the pastoral areas in Qinghai - with the case study of the grassland degradation in the Three Rivers, Qinghai, Pratacul, 18, 19-23, 2009 (in Chinese).

Li, W. and Zhang, Y.: Impacts of plateau pikas on soil organic matter and moisture content in alpine meadow, Ac. Theriol. Sin., 26, 331-337, 2006 (in Chinese with English abstract).

Li, X., Gao, J., Brierley, G., Qiao, Y., and Zhang, J.: Rangeland degradation on the Qinghai-Tibet Plateau: Implications for rehabilitation, Land Degrad. Dev., 24, 72-80, 2011.

Liu, Y., Fan, J., Harris, W., Shao, Q., Zhou, Y., Wang, N., and Li, Y.: Effects of plateau pika (Ochotona curzoniae) on net ecosystem carbon exchange of grassland in the Three Rivers Headwaters region, Qinghai-Tibet, China, Plant Soil, 366, 491-504, 2013.

Luo, T., Pan, Y., Ouyang, H., Shi, P., Luo, J., Yu, Z., and Lu, Q.: Leaf area index and net primary productivity along subtropical to alpine gradients in the Tibetan Plateau, Glob. Ecol. Biogeogr., 13, 345-358, 2004.

Motohka, T., Nasahara, K., Oguma, H., and Tsuchida, S.: Utility of Green-Red Vegetation Index for remote sensing of vegetation phenology, Remote Sens., 2, 2369-2387, 2010.

Qin, Y., Yi, S., Ren, S., Li, N., and Chen, J.: Responses of typical grasslands in a semiarid basin on the Qinghai-Tibetan plateau to climate change and disturbances, Environ. Earth Sci., 71, 14211431, 2014.

Qin, Y., Chen, J., and Yi, S.: Plateau pikas burrowing activity accelerates ecosystem carbon emission from alpine grassland on the Qinghai-Tibetan Plateau, Ecol. Eng., 84, 287-297, 2015a. 
Qin, Y., Yi, S., Chen, J., Ren, S., and Ding, Y.: Effects of gravel on soil and vegetation properties of alpine grassland on the QinghaiTibetan plateau, Ecol. Eng., 74, 351-355, 2015 b.

Ren, S., Yi, S., Chen, J., Qin, Y., and Wang, X.: Comparisons of alpine grassland fractional vegetation cover estimation using different digital cameras and different image analysis methods, Pratacultural Science, 31, 1007-1013, 2014 (in Chinese with English abstract).

Salami, E., Barrodo, C., and Pastor, E.: UAV flight experiments applied to the remote sensing of Vegetated areas, Remote Sens., 6, 11051-11081, 2014.

Scurlock, J. M. O., Johnson, K., and Olson, R. J.: Estimating net primary productivity from grassland biomass dynamics measurements, Glob. Change Biol., 8, 736-753, 2002.

Shang, Z. and Long, R.: Formation causes and recovery of the "Black Soil Type" degraded alpine grassland in Qinghai-Tibetan Plateau, Front. Agric. China, 1, 197-202, 2007.

Smith, A. T. and Foggin, J. M.: The plateau pika (Ochotona curzoniae) is a keystone species for biodiversity on the Tibetan plateau, Anim. Conserv., 2, 235-240, 1999.

Sun, F., Chen, L., Liu, L., Liu, W., Cai, Y., and Pete, S.: Effects of plateau pika activities on seasonal plant biomass and soil properties in the alpine meadow ecosystems of the Tibetan Plateau, Grassland Sci., 61, 195-203, 2016.

Wandwei, M., Steele, B., and Harris, R. B.: Demographic responses of plateau pikas to vegetation cover and land use in the Tibet Autonomous Region, China, J. Mammal., 94, 1077-1086, 2013.

Wang, G., Li, Y., Wang, Y., and Wu, Q.: Effects of permafrost thawing on vegetation and soil carbon pool losses on the QinghaiTibet Plateau, China, Geoderma, 143, 143-152, 2008.

Wei, X., Li, S., Yang, P., and Cheng, H.: Soil erosion and vegetation succession in alpine kobresia steppe meadow caused by plateau pika -A case study of Nagqu County, Tibet, Chinese Geogr. Sci., 17, 75-81, 2007.

Wilson, M. C. and Smith, A. T.: The pika and the watershed: The impact of small mammal poisoning on the ecohydrology of the Qinghai-Tibetan Plateau, Ambio, 44, 16-22, doi:10.1007/s13280-014-0568-x, 2014.
Yang, Z. and Jiang, X.: The harm of plateau pika on grassland vegetation and its control threshold value, Pratacultural Sci., 19, 6365, 2002 (in Chinese with English abstract).

Yi, S.: FragMAP: A tool for the long-term monitoring and analysis of small-scale habitat fragmentation using an unmanned aerial vehicle, Int. J. Remote Sens., doi:10.1080/01431161.2016.1253898, in press, 2016.

Yi, S., Zhou, Z., Ren, S., Xu, M., Qin, Y., Chen, S., and Ye, B.: Effects of permafrost degradation on alpine grassland in a semiarid basin on the Qinghai-Tibetan Plateau, Environ. Res. Lett., 6, 045403, doi:10.1088/1748-9326/6/4/045403, 2011.

Zhang, J., Zhang, L., Liu, W., Qi, Y., and Wo, X.: Livestockcarrying capacity and overgrazing status of alpine grassland in the Three-River Headwaters region, China, J. Geogr. Sci., 24, 303-312, 2014.

Zhang, Y., Dong, S., Gao, Q., Liu, S., Liang, Y., and Cao, X.: Responses of alpine vegetation and soils to the disturbance of plateau pika (Ochotona curzoniae) at burrow level on the Qinghai-Tibetan Plateau of China, Ecol. Eng., 88, 232-236, 2016.

Zhou, H., Zhou. L., Zhao, X., Yan, Z., Liu, W., and Shi, Y. :The degraded process and integrated treatment of 'black soil beach' type degraded grassland in the source regions of Yangtze and Yellow Rivers, China J. Ecol., 22, 51-55, 2003 (in Chinese with English abstract).

Zhou, Z., Yi, S., Chen, J., Ye, B., Sheng, Y., Wang, G., and Ding, Y.: Responses of alpine grassland to climate warming and permafrost thawing in two basins with different precipitation regimes on the Qinghai-Tibetan Plateau, Arct. Alp. Res., 47, 125-131, 2015. 